\title{
Performance management: een kernactiviteit voor effectieve bedrijfsvoering
}

\section{Inleiding op het thema}

\author{
Paul Jansen en Jaap Paauwe
}

Op het gebied van human resource management (HRM) is performance management één van de belangrijkste activiteiten, naast aandacht voor zaken als talent management, leiderschapsontwikkeling en personeelsplanning. Dat geld t vooral in een tijd van vergrijzing, employer branding en HR-herstructurering waarbij gebruikgemaakt wordt van shared service centres (Paauwe en Farndale, 2007). Performance management wordt gezien als de sleutel tot het maximaliseren van return on investment in human capital en dus het creëren van een mogelijk concurrentievoordeel voor de organisatie.

Performance management omvat een brede reeks activiteiten (Roberts, 2001), die een brug slaan tussen het managen van het presteren van medewerkers, teneinde de performance van de gehele organisatie te verbeteren (Castka et al., 2003). Dus, performance management 'heeft te maken met de uitdaging die organisaties ondervinden in het definiëren, meten en stimuleren van medewerkerperformance met als uiteindelijk doel het verbeteren van de organisatieperformance' (Den Hartog, Boselie en Paauwe, 2004, p. 556). Deze opvatting wordt gesteund door DeNisi (2000), die stelt dat performance management verwijst naar een reeks activiteiten uitgevoerd door een organisatie om de performance van een persoon, groep of afdeling te verbeteren, met als uiteindelijk doel het verbeteren van de organisatie-effectiviteit. In concreto kunnen we dan denken aan activiteiten als het stellen van doelen, beoordelen, belonen, training en opleiding, en loopbaanbeleid.

De laatste twee decennia is performance management steeds belangrijker geworden, omdat leidinggevenden voortdurend onder druk staan om het presteren van hun organisatie te verbeteren (Holloway et al., 1999, p. 351).

Voor wat betreft de empirische bewijsvoering van de effectiviteit van performance management-systemen lopen de meningen nogal uiteen. Diverse auteurs (bijvoorbeeld
Armstrong, 2000; Molleman en Timmerman, 2003; Otley, 1980) benadrukken de vele voordelen ervan, terwijl anderen (bijvoorbeeld Rademan en Vos, 2001; Furnham, 2004; Hazard, 2004) zo hun kritiek en twijfels hebben als het gaat om de effectiviteit ervan. Conceptueel-theoretisch gezien richtte het onderzoek zich veelal op één aspect van performance management, namelijk het meten van de prestatie. Het accent lag dan op het evalueren van de prestatie en het op grond daarvan geven van feedback. Echter, een meer omvattende benadering zou ons begrip inzake de mogelijkheden voor de daadwerkelijke effectiviteit van performance management-systemen kunnen vergroten. Richten we onze aandacht op de uitvoering en werking van performance management-systemen, dan is er nog nauwelijks onderzoek gedaan naar de omstandigheden waaronder de bijdrage van performance management geoptimaliseerd kan worden.

\section{Historie}

Het meten van prestaties dateert al vanaf het midden van de negentiende eeuw, vooral gestimuleerd vanuit de 'boekhoud'-functie en het daarmee samenhangende bewaken en registreren van kosten. Binnen het systeem van massafabricage kon de duur van de achtereenvolgende taken gemeten worden, zowel qua tijd als benodigd budget per taak. Het meten van de prestatie was eerder gericht op het meten van specifieke activiteiten omwille van het registreren van de ermee gepaard gaande kosten, dan dat het zou kunnen bijdragen aan het verbeteren van het presteren van zowel medewerkers als organisatie. En dat laatste is nadrukkelijk wel de bedoeling als we het hebben over performance management (Radnor en McGuire, 2004). Het bepalen van financiële kengetallen, vooral gericht op de directe kosten van arbeid en materiaal, was betrekkelijk eenvoudig in te voeren in dit soort productieorganisaties (Neely et al., 1995). 
In het begin van de jaren tachtig van de vorige eeuw werd echter duidelijk dat alleen gebruikmaken van financiële kengetallen geen nauwkeurige voorspelling geeft van het succes of falen van een organisatie (Peters en Waterman, 1982). Het overwegend benadrukken van kengetallen vanuit een accountingperspectief heeft geleid tot een focus op de korte termijn, waarbij managers vooral gericht zijn op het behalen van gestelde (financiële) doelen in termen van verkopen, marktaandeel, enzovoort, met als risico dat een dergelijke gerichtheid ten koste gaat van de duurzaamheid van de organisatie op de lange termijn. Rond die tijd ontwikkelden Kaplan en Norton (1992) hun 'balanced scorecard', die zich richtte op het in kaart brengen en meten van meer indicatoren dan alleen financiële. $\mathrm{Zij}$ stelden vier perspectieven voor - financieel, klant, interne bedrijfsprocessen en leren en groei - waarbij het streven erop gericht is om korte- en langetermijndoelstellingen meer met elkaar in evenwicht te brengen. Dit maakte de weg vrij voor de vormgeving van performance management als een meer 'holistisch' systeem (Thorpe en Beasley, 2004; Neely, 1999).

\section{Performance management als integraal onderdeel van management}

Deze visie op performance management als een meer omvattend systeem zorgt ervoor dat de resultaten van het meten ook daadwerkelijk gebruikt worden door het management om te komen tot verbetering van de prestatie. Performance management wordt dan een integraal en continu onderdeel van het organiseer- en managementproces. Dat leidt ertoe dat performance management-systemen in plaats van te worden gebruikt voor beheersing en controle (de'politie'-rol), een bredere betekenis krijgen in de dagelijkse bedrijfsvoering voor het evalueren en ontwikkelen van medewerkers en hen te stimuleren te komen tot betere resultaten. Tegelijkertijd zorgen ze ervoor dat er sprake is van een goede afstemming tussen individuele doelen en het doel van de organisatie als geheel (Roberts, 2001).

Performance management is ontwikkeld om diverse, uiteenlopende doelen te bereiken (bijvoorbeeld Armstrong, 2000; Millett, 1998; Molleman en Timmerman, 2003). Dat zien we ook terug in de opsomming van Baron en Kreps (1999):

- een uitgebreide evaluatie voor het verbeteren van de afstemming tussen functie en persoon;

- communicatie over organisatiewaarden en doelen;

- het aanbieden van informatie over zelfverbetering, training en ontwikkeling en carrièreontwikkeling;

- het verbinden van beloning aan individuele en/of team performance;

- het verzamelen van informatie voor strategieën wat betreft aanname;
- het valideren van HR-praktijken inclusief beoordeling en beloning, retentie en downsizing;

- en input voor juridische verdediging (bijvoorbeeld wanneer een organisatie van een medewerker af probeert te komen vanwege slecht presteren).

Deze doelen kunnen echter, bij nadere beschouwing, op basis van Aguinis (2007) en Armstrong (2000) als volgt samengevat worden:

- Strategische doelen: performance management-systemen zijn ontwikkeld om het topmanagement te helpen strategische organisatiedoelen te bereiken. Door organisatiedoelen te koppelen aan individuele doelen, versterkt het performance management-systeem gedrag dat gericht is op en consistent is met het realiseren van die organisatiedoelen (Aguinis, 2007; Cleveland et al., 1989; zie ook Paauwe et al., bijdrage in dit themanummer). Bovendien vervullen performance managementsystemen een belangrijke rol als het gaat om het inventariseren van talent ('high potentials') door het verstrekken van informatie over de competenties van het huidige personeel (in termen van vaardigheden, bekwaamheden en de mogelijkheden voor doorgroei naar een hogere functie). Dat maakt personeelsplanning mogelijk, waarbij geanticipeerd wordt op toekomstige behoeften binnen en buiten de organisatie (bijvoorbeeld nieuwe product-marktcombinaties), het bepalen van prioriteiten ter zake, het efficiënt alloceren van personeel en het inschatten van toekomstige opleidingsbehoeften (Aguinis, 2007; Cleveland et al., 1989).

- Traditionele, meer tactische HR-doelen: performance management-systemen zijn ontwikkeld om bruikbare informatie te verstrekken voor het maken van HR-gerelateerde beslissingen, zoals salarisaanpassingen, promoties, behoud van medewerkers dan wel beëindiging van dienstverband, (h)erkenning van superieure individuele prestaties, het achterhalen van slechte prestaties en het toekennen van salarisverhogingen op basis van geleverde prestaties (zie verder Paauwe et al., bijdrage in dit themanummer). Daarnaast geeft deze informatie managers de mogelijkheid tot het voortdurend coachen van hun medewerkers, door het aanwijzen en bespreken van zwakke en sterke punten en het zo veel mogelijk achterhalen van de oorzaken ervan (Aguinis, 2007; Cleveland et al., 1989).

\section{Faciliteren van de effectiviteit van performance management-systemen}

Ondanks de logica ervan, is het bewijs dat performance management een belangrijke rol speelt voor het succes van de organisatie verre van overtuigend (Glendinning, 2002). Performance management 'is één van de meest geprezen, bekritiseerde en besproken management tools van de 
laatste jaren' (Lawler, 1994, p. 16) en 'het blijft een grote bron van frustratie voor managers' (McDonald en Smith, 1995, p. 59). Aan de ene kant zien we duidelijke voorstanders van performance management, die op grond van empirisch onderzoek (bijvoorbeeld Armstrong, 2000; Molleman en Timmerman, 2003) bewijs leveren dat organisaties met performance management-programma's beter presteren dan organisaties zonder zulke programma's. Voorts zijn er ook onderzoeksuitkomsten die erop wijzen dat organisaties die het in hun sector slechter deden dan het gemiddelde van de branche, aanzienlijke progressie boekten na het implementeren van een performance management-systeem. (Glendinning, 2002; McDonald en Smith, 1995). Aan de andere kant zien we ook auteurs die op basis van empirisch onderzoek aantonen dat performance management niet werkt en leidt tot ontevredenheid bij zowel de medewerkers als het management. Een nadere verkenning van het achterhalen van de oorzaken van een negatieve of gebrekkige werking van systemen voor performance management wijst dan op zaken als het niet goed up-to-date houden van het systeem en te veel focus op individueel functioneren in plaats van team- of afdelingsfunctioneren (Lawler, 1994). Cruciaal voor het al dan niet succesvol zijn, lijkt ook te zijn: de wijze waarop het systeem is geïmplementeerd. Daar waar performance management-systemen slecht worden ingevoerd en onderhouden, kunnen ze eerder tot last zijn en problemen geven in de werkgever-werknemerrelatie, dan een instrument dat motiveert (Glendinning, 2002; Hazard, 2004).

De artikelen in dit themanummer hebben alle betrekking op deze toepassingsvoorwaarden. Zo geeft Jansen een overzicht van onder welke condities feedback geven werkt, en vooral waarvoor het dan werkt. Een belangrijke conditie blijkt hoe er wordt omgegaan met fouten. Omdat bovendien iedere feedbackgever op een eigen wijze oordeelt, wordt steeds vaker gewerkt met meerdere beoordelaars; dat roept de vraag op hoe beoordeelden omgaan met feedback uit meerdere bronnen. Paauwe, Biron en Farndale plaatsen de effectiviteit van performance managementsystemen in de context van de 'signalling theory'. Op basis van grootschalig internationaal onderzoek onder multinationals komen zij tot vier systeemfactoren die prestatiemanagement bevorderen en het verschil maken tussen een effectieve dan wel een ineffectieve uitwerking ervan. Van Veen-Dirks gaat in op de relatie tussen het belang van (niet-)financiële prestatiemaatstaven en twee hoofddoelstellingen van prestatiemeting: evaluatie of beloningsbepaling. De vraag wordt gesteld, en beantwoord, in hoeverre het wenselijk is dat er sprake is van verschillende prestatiemaatstaven voor beide doelstellingen.

Al met al richt het denken over performance management zich meer en meer op de menigvuldigheid aan voorwaarden waaronder het bijdraagt aan zowel personele als organisatieprestaties. Duidelijk is dat daarbij wordt geput uit meerdere disciplines, zoals bedrijfspsychologie, management accounting, organisatiekunde en personeelswetenschappen. Dat maakt onderzoek van performance management bij uitstek een bedrijfswetenschappelijke aangelegenheid.

Prof. dr. P.G.W. Jansen is sedert 1992 hoogleraar

Bedrijfspsychologie aan de Faculteit der Economische

Wetenschappen en Bedrijfskunde, VU Amsterdam. Hij

studeerde (cum laude) Mathematische Psychologie aan de

Katholieke Universiteit Nijmegen en was werkzaam op het

ministerie van Binnenlandse zaken, bij de Rijks

Psychologische Dienst, en bij PTT/KPN. Van 1995-2001 is hij

deeltijd directeur van het Limperg Instituut, Interuniversitair

Onderzoeksinstituut voor Accountancy.

Prof. dr. J. Paauwe is als hoogleraar/voorzitter verbonden

aan het Departement HR-Studies, Faculteit Sociale en

Gedragswetenschappen, Universiteit van Tilburg en

daarnaast als deeltijdhoogleraar verbonden aan de Erasmus

Universiteit Rotterdam, Faculteit der Economische

Wetenschappen/iBMG. Daarnaast is hij als academic director

en fellow verbonden aan TIASNIMBAS Business School, en

tevens fellow van de Judge Business School, Cambridge

University (UK). 
Literatuur

Aguinis, H. (2007), Performance management (2nd edition), Upper Saddle River, $\mathrm{NJ}$ : Pearson Prentice Hall.

- Armstrong, M. (2000), Performance management practice: Key practices and practical guidelines, London: Kogan Page.

Baron, J.N. en D.M. Kreps (1999) Strategic human resource management: Frameworks for general managers, Danvers, MA: John Wiley \& Sons, Inc.

— Castka, P., C. Bamber en J. Sharp (2003), Measuring teamwork culture: The use of a modified EFQM model, Journal of Management Development, vol. 22, pp. 149-170.

- Cleveland, J.N., K.R. Murphy en R.E. Williams (1989), Multiple uses of performance appraisal: Prevalence and correlate, Journal of Applied Psychology, vol. 74, pp. 130-135.

- DeNisi, A.S. (2000), Performance appraisal and performance management: A multilevel analysis. In: K.J. Klein, en S. Kozlowski (eds), Multilevel theory, research and methods in organizations, pp. 121-156, San Francisco: Jossey-Bass.

-Den Hartog, D.N., P. Boselie en J. Paauwe (2004), Performance management: A model and research agenda, Applied Psychology: An International Review, vol. 53, 556-569.

- Furnham, A. (2004), Performance management systems, European Business Journal, vol. 16, pp. 83-94.

ש Glendinning, P.M. (2002), Performance management: Pariah or Messiah, Public Personnel Management, vol. 31, pp. 161-178.

- Hazard, P. (2004), Tackling performance management barriers, Strategic HR Review, vol. 3, pp. 3-7.
- Holloway, J., G. Francis en M. Hinton (1999), A vehicle for change? A case study of performance improvement in the 'new' public sector, The International Journal of Public Sector Management, vol. 12, pp. 351-365.

- Kaplan, R.S. en D.P. Norton (1992), The Balanced Scorecard - measures that drive performance, Harvard Business Review, vol. 70, no. 1, pp. 71-79.

- Lawler, E. (1994), Performance management: The next generation, Compensation and Benefits Review, vol. 26, pp. 16-20.

- McDonald, D. en A. Smith (1995), A proven connection: Performance management and business results, Compensation and Benefits Review, vol. 27, pp. 59-62.

- Millett, B. (1998), Performance management: A strategic human resource function. In: K. Parry en D. Smith (eds.), Human Resource Management: Contemporary challenges and future direction, pp. 95-114, Toowoomba: USQ Press.

- Molleman, E., en Timmerman, H. (2003), Performance management when innovation and learning become critical performance indicators, Personnel Review, vol. 32, pp. 93-113.

- Neely, A. (1999), The performance measurement revolution: Why now and what next?, International Journal of Operations and Production Management, vol. 19, pp. 205-228.

- Neely, A., M. Gregory en K. Platts (1995), Performance measurement system design. A literature review and research agenda, International Journal of Operations and Production Management, vol. 15, pp. 80-116.
Otley, D.T. (1980), The contingency theory of management accounting: Achievement and prognosis, Accounting, Organizations and Society, vol. 4, pp. 194-208.

- Paauwe, J. en E. Farndale (2007), HR Shared Service Centers in Nederland: Ervaringen, verwachtingen en lessen voor de toekomst, Tijdschrift voor HRM, vol. 10, no. 3, pp. 7-31.

- Peters, T. en R.H. Waterman (1982), In search of excellence. Lessons from America's best-run companies, London: HarperCollins Publishers.

- Rademan, D.J. en H.D. Vos (2001), Performance appraisals in the public sector: Are they accurate and fair?, Journal of Industrial Psychology, vol. 27, pp. 54-60.

- Radnor, A. en M. McGuire (2004), Performance management in the public sector: Fact or fiction?, International Journal of Productivity and Performance Management, vol. 53, pp. 245-260.

- Roberts, I. (2001), Reward and performance management. In: I. Beardwell en L. Holden (eds.), Human Resource Management: A contemporary approach (3rd ed.) (pp. 506558), Edinburgh: Pearson.

- Thorpe, R. en T. Beasley (2004), The characteristics of performance management research: Implications and challenges, International Journal of Productivity and Performance Management, vol. 53, pp. 334344. 